\title{
Víctor L. Urquidi. Trayectoria intelectual de Joseph Hodara
}

\section{Alma Escamilla Cano}

"Al alejarse del hospital en julio de 2004 -relata Joseph Hodara- después de intercambiar últimas sonrisas y palabras con Víctor L. Urquídi, le asaltó un anhelo que, con los avatares del tiempo, se transformó en pertinaz obsesión: trazar algunas huellas de su humano andar". Un mes después, moriría Víctor L. Urquidi. La obsesión de J. Hodara tuvo eco en el Colegio de México, donde encontró, en su Director Javier Garciadiego Dantán, el apoyo personal e institucional necesarios para construir el libro, el cual se publicó en agosto de 2014.

El propósito de J. Hodara fue examinar más de cincuenta años de trabajo, de participación académica y política, y del compromiso que Víctor L. Urquidi asumió con México y América Latina, desde 1940 hasta su muerte; además de reconocer la trascendencia de la influencia de su pensamiento en las políticas públicas que se produjeron en el país durante ese largo período, así como, la importancia que tuvo como formador, inflexible y severo, de investigadores y profesores; entre otros aspectos de su vida.

Joseph Hodara realiza una reseña histórica minuciosa, documentada, rigurosa, crítica, desapasionada, equilibrada y admirativa, de la vida profesional y de la obra de Víctor L. Urquidi (vLu), que comprende los principales aspectos biográficos del protagonista, los rasgos de su carácter y personalidad, el desarrollo de ideas, el análisis de corrientes de pensamiento, $y$

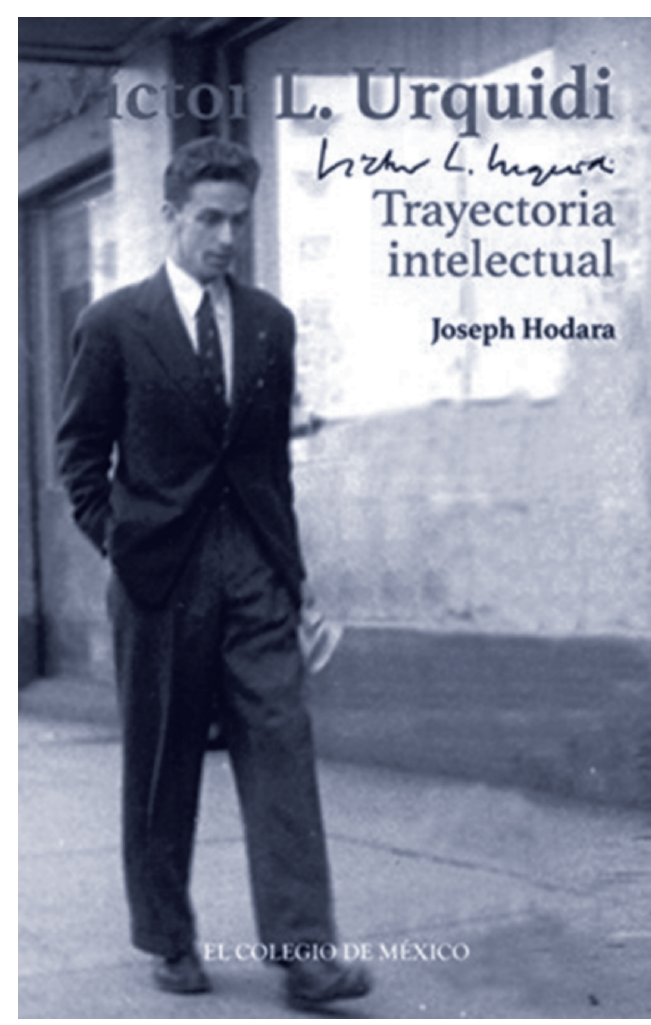

la comprometida defensa y difusión de aquellas en cuya pertinencia creía.

El libro está dividido en cinco grandes títulos y dieciséis subtítulos, todos sugestivos e ingeniosos, que permiten al lector adentrarse en los temas que constituyeron el eje de reflexión y análisis de Víctor L. Urquidi; permiten incluso profundizar pródigamente, ya que el autor nos proporciona más de trecientas ochenta referencias. Además, Joseph Hodara entrevera conceptos e ideas propios que enriquecen analíticamente la descripción y la relatoría, y dejan ver su sólida formación como sociólogo y estudioso de la economía, la semiótica y la filosofía; esta modalidad del relato le 
permite al autor desplegar una visión, a veces polémica, sobre su personaje, situación muy disfrutable para el lector.

Sobre los rasgos de la personalidad de Víctor

L. Urquidi, destaca el autor su condición de "siempre caballero" por su "sensible respeto al otro"; no obstante, aclara que establece distancia, entre tímida y arrogante y que ésta puede ser resultado de la internalización de las características de la élite británica con la que convivió durante su estadía en Inglaterra, en la adolescencia y la época de estudiante de economía. Sin embargo, refiere que su estilo preciso y directo al exponer, le ayudaba a disimular su recalcitrante timidez. Joseph Hodara narra las condiciones de la infancia de Víctor L. Urquidi en el seno de una familia conformada por un padre diplomático y una madre de profesión enfermera y nacionalidad inglesa, y dos hermanas, la cual se desarrolla en diferentes países y se ve interrumpida por la guerra civil española (vivían en España) y por la Segunda Guerra Mundial, lo que obliga a sus padres a enviarlo a Londres.

El inicio y los primeros años de la trayectoria laboral de Víctor L. Urquidi, una vez que regresó a México, en 1940, y que se produjo en octubre de ese año, al ingresar al Banco de México, y posteriormente su paso por el Banco Mundial, y por la Comisión Económica para América Latina (CEPAL), da pie al autor para recordarnos las condiciones precarias para el estudio de la economía que prevalecían en nuestro país en esa época -una sola institución formal-, en contraste con las inquietudes de un egresado de la London School of Economics.

La narración de la designación de VLU como miembro de la delegación mexicana que asistiria a Bretton Woods da pie al autor para obsequiarnos con las principales ideas de John M. Keynes y Harry White sobre el tema de la Conferencia, y de la voluntad y pasión de Don Daniel Cosío Villegas, del propio Urquidi, y de Eduardo Villaseñor, por delinear prolijamente la postura del país en tan importante evento: lograr la flexibilidad indispensable para realizar ajustes cambiarios, concertar defensas en contra de una intromisión excesiva en los asuntos domésticos por parte de intereses foráneos, conseguir que las nuevas instituciones que habrían de fundarse apoyaran no sólo a la Europa destruida -sino también a los países en desarrollo-; postura, siempre bajo la atención y respaldo de las autoridades hacendarias mexicanas. Como colofón a esa importante experiencia en la vida profesional de Víctor L. Urquidi, J. Hodara nos relata los pormenores de la creación de dos importantes organismos financieros internacionales: el Banco de Reconstrucción y Fomento, y el Banco Mundial, el contexto en el que se realizó, y los beneficios que se produjeron en ese momento, aunque, también, refiere el autor, Víctor L. Urquidi las analizará más tarde bajo la perspectiva histórica y su conclusión será más que incisiva.

Refiere, J. Hodara, que a partir del desempeño como funcionario del Banco Mundial, en los años cuarenta, Víctor L. Urquidi, comienza a descubrir su interés por América Latina; se pregunta "si la región constituía en rigor un conjunto económico y políticamente afín y homogéneo". El autor narra diversas experiencias -estudios y viajes- de Urquidi, y aprovecha para plantear las ideas de otros distinguidos latinoamericanistas y la vinculación que éste estableció con ellos, a partir de lo cual, durante mucho tiempo, analizará el Estado y propondrá medidas de política para el desarrollo de la región. Le preocupaba -destaca J. Hodara- la tendencia en varios países a depender del extranjero con 


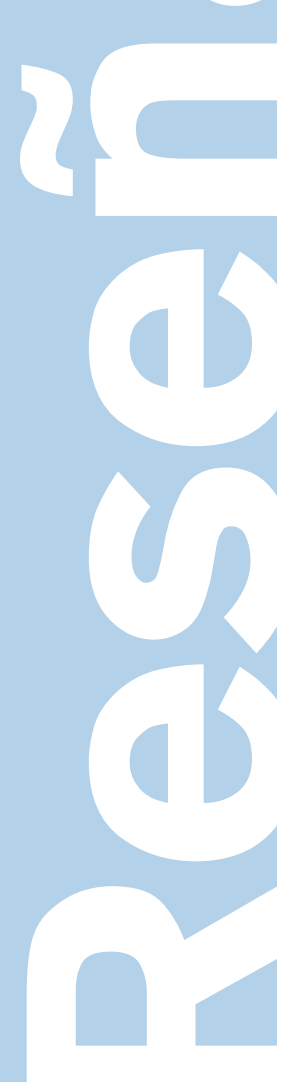

la exportación de unos cuantos productos primarios que tienen demanda desigual, pues, consideraba que la viabilidad de la región latinoamericana dependería de su capacidad para instituir acuerdos y prácticas de complementación; así comienza a fortalecerse en su pensamiento la convicción de la conveniencia de una complementación regional de los mercados. De la labor de vLu en este tema, junto con la de otros economistas y estudiosos, surgieron varios acuerdos importantes en la región, tanto de comercio como de cooperación económica, así como la homologación de listas arancelarias. No deja de reconocer J. Hodara que muchas de las ideas promovidas en ese entonces por Urquidi, como el establecimiento de una unión aduanera y la consiguiente liberación del comercio, en paralelo al modelo de sustitución de importaciones, ya se conocían en Europa. Sin embargo, la promoción de su adopción en la zona, tuvo una gran importancia y contribuyó a un mayor desarrollo de algunos países de la región.

Tres vértices del triángulo que J. Hodara denomina "el cálido hogar intelectual" de
Víctor L. Urquidi, lo constituyen la creación del Fondo de Cultura Económica, por Don Daniel Cosío Villegas, en 1934, la publicación de el Trimestre Económico, en 1934, y la fundación de la Casa de España, que se transformará, en 1940, en El Colegio de México, aunados a la docencia que ejercerá durante varios años en la Escuela Nacional de Econo- mía de la Universidad Nacional Autónoma de México. Inicialmente, el Trimestre le permitió verter al castellano importantes textos de economía publicados en otros idiomas; posteriormente, sus textos, asumieron un carácter didáctico, como en el caso de la meticulosa explicación de los componentes teóricos de la macroeconomía, o bien, habrían de caracterizar los comportamientos y tendencias de la economía mexicana. Como profesor en la Escuela Nacional de Economía, se consagra a exponer y a resumir los escabrosos problemas económicos que aguardaban a México; sobre éstos, puso el acento en los imperativos de la industrialización, sin menospreciar la reforma agraria, en la distribución asimétrica de la expansión económica y en la necesidad de aumentar el volumen anual de las inversiones, orientar el ahorro, y sostener el equilibrio en la balanza de pagos.

J. Hodara recrea la influencia que tuvieron en Víctor L. Urquidi otros intelectuales, principalmente filósofos y sociólogos, entre ellos, José Medina Echevarría, Alfonso Reyes y José Gaos, sin cuyo ascendiente las incursiones de Urquidi en la economía habrian sido parciales; esta influencia se manifiesta en una profunda sensibilidad respecto a las dimensiones sociales que debían complementar a las económicas, y en la sostenida curiosidad por los principales aportes de la sociología europea.

La preocupación de Víctor L. Urquidi por el tema fiscal, es relatada por J. Hodara, desde sus primeras apariciones en la 
década de los cincuentas, la cual fue retomada por Urquidi, dos décadas después, de una manera más analítica y documentada. En la primera etapa refiere las dificultades a las que se enfrentaba el estudioso, derivadas de la demagogia en las referencias oficiales y de la falta de datos, lo que impedía llegar a conclusiones terminantes. No obstante, -nos dice el autor- Urquidi puntualiza las razones por las que se comienzan a registrar fuertes tendencias a la concentración del ingreso en pocas manos; entre éstas: el aumento de la actividad comercial, la creciente monetización de la economía, la urbanización acelerada, el rápido desarrollo industrial y de los transportes, y una inflación apenas contenida. A estos elementos añade -cuando amplia el análisis a América Latina- la carencia de una eficiente y significativa representación política de los grupos marginados, la libre concentración y acumulación de la propiedad, las tendencias monopólicas inherentes al sistema, la disparidad en el crecimiento de diferentes sectores, la precaria o inexistente sindicalización laboral, y los regímenes de sucesión y herencia que preservan las disparidades a través de las generaciones.

La plena expansión de la economía mexicana -en la década de los sesentas- detalla J. Hodara- no confunde al pensador, quien identifica plenamente los peligros de la dependencia comercial de México respecto de Estados Unidos y expresa claramente que "los resultados positivos de nuestro comercio exterior sólo se presentarán durante el tiempo en que el país vecino se encuentre en un ciclo de prosperidad, pero, si experimenta un letargo más o menos duradero, las repercusiones serán sombrías para nuestro país". Advierte sobre la necesidad de ponderar con realismo el escenario internacional, pues, de lo contrario, la bonanza de los cincuentassesentas puede quebrarse con rapidez; advertencia que, lamentablemente, no fue tomada en cuenta, concluye Hodara.

Cuando en la década de los ochentas, el declive de nuestra economía se torna sensible y dramático, debido al imprudente manejo de los recursos petroleros -nos refiere el autor de la biografía intelectual- Víctor $\mathrm{L}$. Urquidi no vacila en concluir que ello se debió a "una larga historia de centralización, autoritarismo e ineficacia, a los que se suma un populismo desorientado", y considera que dicho declive no será fácil de contrarrestar.

Nos comenta J. Hodara, que desde sus inicios como investigador en el Colmex, Víctor L. Urquidi pondrá énfasis en los estudios de población -que apenas principiaban en el país- por considerar que el aceleramiento demográfico constituía una variable importante que contrastaba con la lentitud del crecimiento industrial. Esta clara tendencia ocasionada por el declive constante de la mortalidad, mientras las tasas de fecundidad mostraban propensiones ascendentes, lo lleva a concluir que el ensanchamiento poblacional "gravitará negativamente en el ahorro 
interno, y obligará al sector público -si es socialmente sensible- a aumentar los gastos en educación, salud y servicios, a expensas de inversiones productivas en el corto plazo". Más tarde, vinculará el explosivo crecimiento poblacional con los daños acumulativos al medio ambiente. Las ideas de Urquidi, junto con las de Gustavo Cabrera, llevarán a la creación del Consejo Nacional de Población, en 1974.

El dinamismo de la población mexicana, lleva a Víctor L. Urquidi a replantearse un tema recurrente en su quehacer intelectual, la necesidad de una reforma fiscal, ya que considera que "el crecimiento poblacional constituye una presión social que tiene consecuencias económicas, pues ha contribuido a mantener la distribución desigual del ingreso y posiblemente a empeorarla"; razón por la cual, considera, que "es indispensable elevar las tasas de inversión, lo que depende de una rectificación fiscal". J. Hodara nos comenta que Víctor L. Urquidi se duele

$$
\text { de que las autoridades se rehusaban a }
$$
emprender la necesaria reforma fiscal, pues esa cerrazón obligaba a los gobiernos a recurrir cada vez más a fuentes externas de crédito, con el consiguiente endeudamiento externo.

Otro gran tema abordado por el autor es la preocupación de Víctor L. Urquidi sobre la ciencia, la tecnología y la educación, en países en desarrollo, México en particular. Sobre el tema, Víctor L. Urquidi no sólo plasma su análisis y reflexiones en múltiples artículos y ensayos, sino es promotor de la creación de instituciones y organismos dirigidos tanto a incentivar el análisis prolijo y sistémico de las interrelaciones de estos factores con el crecimiento económico, además de diseñar e impulsar proyectos institucionales que permitieron multiplicar el acervo científico, tecnológico y educativo como complemento indispensable para el desarrollo. En la década de los sesentas, el interés de Víctor L. Urquidi, y otros pensadores, sobre estos temas reclamaron la atención de los jefes de Estado en torno a la urgencia de formular políticas en favor de la ciencia y la tecnología, las cuales se puntualizaron en la Declaración de Punta del Este (abril de 1967). Así mismo, la Organización de Estados Americanos (OEA) y el Banco Interamericano de Desarrollo (BID) se comprometieron a alentar la cooperación con ese propósito.

Nos relata J. Hodara la importante influencia que tuvieron las ideas de Urquidi, sobre la necesaria articulación de la promoción de la ciencia y la tecnología con las necesidades del desarrollo económico, y sobre la independencia necesaria, en la materia, respecto al exterior, sobre la creación del Consejo Nacional de Ciencia y Tecnología (Conacyt), en 1970, y en la 
publicación del primer Programa Nacional de Desarrollo Científico y Tecnológico, en 1974, en cuya formulación Urquidi tuvo activa participación. Cabe señalar que J. Hodara no duda en poner de relieve las observaciones, a veces injustas, que hiciera Urquidi sobre el Conacyt, en la etapa posterior al sexenio de su creación.

En la década de los setentas, dos acontecimientos motivan fuertemente los quehaceres intelectuales de Víctor L. Urquidi: la Cumbre Mundial sobre Medio Ambiente y Desarrollo, que se llevó a cabo en 1972, en Estocolmo, y el surgimiento del Club de Roma. La primera asumió el propósito principal de plantear y cuestionar la viabilidad en el largo plazo de la sociedad humana, considerando los daños ecológicos causados por la negligente conducta de gobiernos y personas -nos recuerda J. Hodara-, la segunda nace como un organismo no gubernamental (ONG), que convocó a científicos e intelectuales para especular en torno a las fronteras últimas del quehacer económico y social en el finito planeta tierra.

Víctor L. Urquidi hizo suyas las inquietudes mencionadas, por el resto de su vida, insistiendo, desde los primeros trabajos, en la necesidad de comprender de manera cabal las interacciones económicas, los efectos y las retroalimentaciones, así como, las causas directas e indirectas de los deterioros registrados en los recursos naturales. En sus escritos, vLu sugiere un orden temático para mejor apreciar la índole y las ramificaciones del tema: la consecuencia general de los programas generales (sic) de protección ambiental; el grave dilema ambiente/desarrollo a que se enfrentan los países pobres; el papel de los incentivos y los castigos como instrumentos para inducir a productores y consumidores a emprender conductas en pro del ambiente. Urquidi desarrolló esta temática aplicando un instrumental analítico con base en conceptos teóricos y de medición de punta (Pigou, D.H. Meadows, entre otros), siempre con los ojos muy abiertos a la realidad circundante.

Comenta J. Hodara, que dos décadas después, la visión de Urquidi no es muy optimista, según se desprende de sus conclusiones: "La idea del desarrollo sustentable no ha penetrado en las sociedades ni en los gobiernos al grado de que sea una base firme de formulación de políticas de desarrollo....En tanto prevalezcan los intereses más inmediatos de los principales países industriales del mundo... el desarrollo sustentable puede no pasar de ser una elegante quimera...Más ¿̇cuál otro camino le queda a la humanidad?". Quedan muchos puntos por tocar en esta apretada reseña, sin embargo, cabe destacar que, para quienes estudiamos economía y hemos practicado la profesión durante muchos años, el libro de J. Hodara sobre Víctor L. Urquidi es un repaso didáctico y ameno de las corrientes de pensamiento económico y político, en México y en América Latina, principalmente, así como, de las políticas públicas, los programas e instituciones, a que éste dio lugar. 



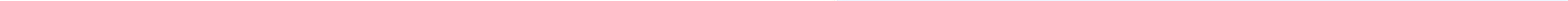

